\title{
Factors Influencing Life Satisfaction in Korean Baby-boomer Men with Drinking Problems
}

\author{
Kim, Minju
}

Department of Nursing, Dong-A University

Purpose: The purpose of this study was to examine the levels of life satisfaction and identify factors influencing life satisfaction in Korean baby-boomer men with drinking problems. Methods: The study used cross-sectional design with secondary analysis of the 7th data of Korean Welfare Penal Study collected in 2012 from 6,000 Korean households. Among 1,572 baby-boomers born between 1955 and 1963, 349 men with a drinking problem were selected as a sample by the Alcohol Use Identification Test (AUDIT) scores. Levels of depression, self-esteem, and life satisfaction were measured. Descriptive statistics, t-tests, ANOVA, Pearson's correlation coefficients, and stepwise multiple regression were conducted with SPSS/WIN 21.0. Results: The findings indicated that the mean AUDIT score was 13.7. Means were 2.8 for depression, 20.2 for self-esteem, and 23.2 for life satisfaction. The results of multiple regression analysis showed that self-esteem, depression, educational level, and levels of problem drinking significantly predicted life satisfaction, explaining $41.1 \%$ of the variance. Conclusion: Problem drinking, depression, and self-esteem were important to improve life satisfaction among Korean baby-boomer men. Further study is necessary to examine the mediating effects of depression and self-esteem in the relationship between problem drinking and life satisfaction.

Key Words: Baby boom, Life satisfaction, Depression, Self-esteem, Drinking

\section{INTRODUCTION}

\section{Need for Study}

With dramatic shifts in life expectancy over the past century, the period of life after middle age is longer. Thus, it is important for people to not only live longer, but also to live well. According to Statistics Korea (2010a), the elderly population is expected to increase from $11.4 \%$ in 2010 to $20 \%$ in 2020 and $32.4 \%$ in 2030. The aging of Korean baby boomers who were born in between 1955 and 1963 contributes to the increase of the elderly population that accounted for $14.6 \%$ of the Korean population in 2010 (Statistics Korea, 2010a). Korean baby boomers are different from the current elderly generation. They are more educated and independent (Jung, 2012). They have strong responsibilities for their parents as well as for grown children, but their expectation for supporting from their children when they are old is rela- tively low (Jung, 2012). Korean baby boomers play significant roles in family as well as the entire society. They have higher satisfaction with their current life compared to the older people. In addition, this unique cohort group is interested in their quality of life, especially in their older life (Chung \& Lee, 2012).

People with drinking problems have relatively lower life satisfaction compared to those with no drinking problem (Strine, Chapman, Balluz, Moriarty, \& Mokdad, 2008). In the United States, rates of heavy alcohol use have been shown to be higher among baby boomers than in the earlier cohorts (DHHS, 2000; Koenig, George, \& Schneider, 1994). Alcohol has been generally accepted in Korean society to keep a relationship with friends or business partners (Ryu, Crespi, \& Maxwell, 2013; Weatherspoon, Park, \& Johnson, 2001). The results of the Korea National Health \& Nutrition Examination Survey in 2011 showed that $77.6 \%$ of men and 44.2 $\%$ of women drank alcohol monthly. High-risk drinking

\footnotetext{
Corresponding author: Kim, Minju

Department of Nursing, Dong-A University, 32 Daesingongwon-ro, Seo-gu, Busan 602-714, Korea.

Tel: +82-51-240-2674, Fax: +82-51-240-2920, E-mail: mjkim@dau.ac.kr
}

- This work was supported by Dong-A university research fund.

투고일: 2013년 11월 12일 / 수정일: 2013년 11월 25일 / 게재확정일: 2013년 11월 25일 
rate was $26.0 \%$ in men and $6.3 \%$ in women (Mininstry of Health and Welfare, 2012). In Korea, alcohol use is estimated to cause $8.9 \%$ of all death, compared with 3.8\% of all deaths in the world (Statistics Korea, 2010b). Men in their 50 60s, including baby boomers, showed the highest weekly heavy drinking rate and highest rates of drunk driving experience (Ministry of Health and Welfare, 2012), which is consistent with the US data (DHHS, 2000). It suggests that the prevalence of problem drinking among older adults may increase as the baby-boomer cohort enters the senior years. Excessive alcohol use may result in adverse health consequences that need more expensive prevention and treatment services (Colliver, Compton, Gfroerer, \& Condon, 2006). According to Kim (2011), baby boomers have more medical expenses per person for alcoholic mental and behavioral disorder compared to older people.

Depression is associated with reduced life satisfaction and increased risk of suicide (Kim, 2002; Lee, Kim, \& Oh, 2003; Park \& Song, 2012). In a previous study, depression was negatively associated with life satisfaction among men with alcoholism (Park, Jin, \& Hoe, 2011). On the other hand, self-esteem had a positive relationship with life satisfaction (Kim \& Kim, 2008; Kwon, 2009). Depression and self-esteem are important for people with drinking problems. Previous studies found positive relationships between drinking and depression (Kwon \& Sung, 2010; Lee \& Lee, 2007). In addition, problem drinkers are more likely to have suicidal ideation compared to other individuals (Kwon, Kim, \& Um, 2011; Yoon, Kim, \& Chae, 2010). Kwon (2009) reported that older adults with drinking problems showed high level of depression and low levels of self- esteem and life satisfaction.

Even though life satisfaction in people with drinking problem is significantly low (Donovan, Mattson, Cisler, Longabaugh, \& Zweben, 2005), only few studies investigated life satisfaction in people with drinking problem. In addition, many studies on alcohol use have focused on older adults (Baik, 2011; Kwon, 2009; Kwon et al., 2011; Yoon et al., 2010), college students (Noh \& Jeong, 2003), middle aged women (Hoe \& Son, 2011), and general adults (Kwon \& Kim, 2004; Kwon \& Sung, 2010; Lee \& Lee, 2007). No study examined life satisfaction in Korean baby boomers with drinking problem. As the baby boomers are getting older, their life satisfaction could be reduced because of adverse health consequences of alcohol use (Colliver et al., 2006). Thus, it is necessary to examine the characteristics of Korean baby boomers, especially men, with drinking problems because of their high rates of heavy drinking, and to identify factors related to their life satisfaction. Especially, baby-boomer men should be targeted because they are more likely to engage in binge drinking (Ministry of Health and Welfare, 2012) and have higher medical expenses per person for alcohol related mental and behavioral disorders compared to women (Kim, 2011). Understanding the factors that influence life satisfaction among baby- boomer men with drinking problem is important to reduce the risk of adverse health consequences and the numbers of people who may need prevention and treatment services.

\section{Purpose of Study}

The purpose of this study was to examine the level of life satisfaction and to identify factors influencing life satisfaction in Korean baby-boomer men with drinking problems. Specific aims are to: examine socio-demographic characteristics and levels of problem drinking, depression, self-esteem, and life satisfaction,; examine the levels of life satisfaction by socio-demographic characteristics,; explore the relationship among problem drinking, depression, self-esteem, and life satisfaction,; and identify factors influencing life satisfaction in Koran baby-boomer men with drinking problems.

\section{METHODS}

\section{Study Design}

This study used a cross-sectional design using a secondary analysis of data, that are part of the 7 th year data of the Korean Welfare Penal Study collected in 2012 from 6,000 households.

\section{Participants}

The original Korean Welfare Penal Study was conducted between February and June in 2012. Interviewers asked questions regarding socio-demographic characteristics, welfare, and health to participants and recorded their answers. A total of 14,604 participated in the Korean Welfare Penal Study.

The target population of this study was baby-boomer men with drinking problems. Inclusion criteria were men who were born in between 1955 and 1963 in Korea and obtaining a score of 8 or more on the Alcohol Use 
Disorder Identification Test (AUDIT) based on the scoring system of the World Health Organization (WHO) (Babor, Higgins-Biddle, Saunders, \& Monteiro, 2001). Overall, 1,572 baby boomers ( 755 men and 817 women) participated in the Korean Welfare Penal Study. Through AUDIT, 349 (46.3\%) men and 43 (5.3\%) women were identified to have drinking problem. Hence, this study examined the levels of life satisfaction in 349 Korean baby-boomer men with drinking problems.

\section{Measurements}

\section{1) The Alcohol Use Disorder Identification Test}

AUDIT is a 10-item scale developed by WHO to determine harmful alcohol consumption (Babor et al., 2001). It includes three domains, alcohol consumption, alcohol dependence, and alcohol-related problems measured on a 4-point of Likert scale, with possible scores ranging from 0 40. Based on WHO's scoring system of the AUDIT, total scores of 8 or more for men ( 7 for women and older adults) indicate a hazardous and harmful alcohol use, as well as possible alcohol dependence (Babor et al., 2001). Higher scores indicate greater severity of alcohol problems and dependence. The Cronbach's alpha was .85 in this study.

\section{2) Life Satisfaction}

Life satisfaction scale comprises 7 domains, including health, family income, living environment, family relationship, work, social relationship, and leisure time measured on a 5 -point of Likert scale $(1=$ not at all to $5=$ very satisfied). Higher scores indicate high level of life satisfaction. The Cronbach's alpha was .789 in a previous study (Kim \& Kim, 2008) and .75 in this study.

\section{3) Depression}

Depression was measured with the 11-item version of the Center for Epidemiologic Studies Depression Scale (CESD-11) originally comprising 20 items developed by Radloff (1977). The CESD-11 consists of four subscales, including depressed (3 items), positive ( 2 items), somatic ( 4 items), and interpersonal ( 2 items) affects. The items are assessed using a three-point response format $(0=$ hardly ever or never; $1=$ some of the time; $2=$ much or most of the time), with a possible score ranging of from 0 to 33 . Two positively-worded items in the positive affect scale were recoded. Higher scores indicate high level of depression. The Cronbach's alphas were 84 to .90 in Radloff's (1977) study that used the original 20-item CESD. The Cronbach's alpha was .85 in this study.

\section{4) Self-esteem}

Self-esteem was measured with Rosenberg Self-Esteem Scale developed by Rosenberg (1979). It is a 10-item scale with 5 positively worded items and 5 negatively worded items. The items are measured on a 4-point Likert scale $(0=$ strongly disagree to $3=$ strongly agree $)$. Negatively worded items were reversed. High scores indicate higher self-esteem. The Cronbach's alphas of this scale were .77 to .88 in the study by Rosenberg (1979) and .73 in this study.

\section{Ethical Consideration}

Local ethics committee approved this study according to national regulations (IRB No. 2-1040709-AB-N-01201309-HR-01-02). Informed written consent was waived because this study was a secondary research using the data of the Korean Welfare Penal Survey.

\section{Data Analyses}

Data were analyzed with SPSS 21.0. Descriptive statistics, t-tests, and ANOVA with Scheffé test were used to explain the characteristics of participants and identify differences in life satisfaction by variables. Pearson's correlation coefficients were estimated to identify the relationship of life satisfaction with continuous variables, including AUDIT, depression, and self-esteem. To identify factors influencing life satisfaction, stepwise multiple regression analysis was conducted with factors influencing life satisfaction via bivariate tests, except marital status and occupation because one group was too small for further analysis.

\section{RESULTS}

\section{Characteristics of Korean Baby-boomer Men with Drinking Problem}

\section{1) Demographic Characteristics of Baby-boomer Men}

Table 1 shows demographic characteristics of babyboomer men with drinking problems. Baby-boomer men were 53 years old on average, with age ranging from 50 to 58. Most were married (83.7\%) and had a job (88.0\%). In addition, approximately $65.3 \%$ had more than high school education. 
Table 1. Demographic Characteristics of the Study Subjects $(N=349)$

\begin{tabular}{llc}
\hline Characteristics & Categories & $\mathrm{n}(\%)$ or $\mathrm{M} \pm \mathrm{SD}$ \\
\hline Age (year) & & $53.55 \pm 2.56$ \\
& $50 \sim 52$ & $135(38.7)$ \\
& $53 \sim 55$ & $119(34.1)$ \\
& $56 \sim 58$ & $95(27.2)$ \\
Marital status & Yes & $292(83.7)$ \\
& No & $57(16.3)$ \\
Occupation & Yes & $307(88.0)$ \\
& No & $42(12.0)$ \\
Educational & $\leq$ Elementary school & $50(14.4)$ \\
level & Middle school & $71(20.3)$ \\
& High school & $147(42.1)$ \\
& $\geq$ College & $81(23.2)$ \\
\hline
\end{tabular}

2) Levels of AUDIT, depression, self-esteem, and life satisfaction

Mean AUDIT scores was 13.67, with a range of 8 to 40. The mean score of levels of depression was 2.67 (range 0 21), while the mean score of levels of self-esteem was 20.15 (range 7 30). In addition, life satisfaction in baby-boomer men with drinking problems was 23.19 with a range of 9 to 33 (Table 2).

Table 2. Levels of AUDIT, Depression, Self-esteem, and Life Satisfaction $(N=349)$

\begin{tabular}{lccc}
\hline Variables & M \pm SD & Min & Max \\
\hline AUDIT & $13.67 \pm 5.41$ & 8 & 40 \\
Depression & $2.76 \pm 4.11$ & 0 & 21 \\
Self-esteem & $20.15 \pm 4.13$ & 7 & 30 \\
Life satisfaction & $23.19 \pm 4.02$ & 9 & 33 \\
\hline
\end{tabular}

AUDIT=Alcohol use disorders identification test.

\section{Life Satisfaction by Demographic Characteristics}

Life satisfaction differed by marital status, working status, and educational level (Table 3). Baby-boomer men having a partner $(\mathrm{t}=6.42, p<.001)$ and a job $(\mathrm{t}=7.56, p<$ .001) showed higher level of life satisfaction. In addition, educational level was associated with life satisfaction $(\mathrm{F}=9.50, p<.001)$. Participants with more than college education reported higher level of life satisfaction compared to those with less than middle school education. However, life satisfaction was not significantly different by age.

\section{Correlations among AUDIT, Depression, Self-esteem, and Life Satisfaction}

Table 4 shows the results of correlations among AUDIT, depression, self-esteem, and life satisfaction. Life satisfaction was positively associated with self-esteem ( $\mathrm{r}=$ $.60)$ and negatively associated with AUDIT $(r=-.28)$ and depression $(r=-.45)$.

\section{Factors Influencing Life Satisfaction}

Stepwise multiple regression analysis was conducted to identify factors influencing life satisfaction, including educational level, AUDIT, depression, and self-esteem (Table 5). Tests for multicollinearity indicated that a very low level of multicollinearity was present (Tolerance= 0.66 to $0.93 ; \mathrm{VIF}=1.08$ to 1.51 ). The results of the regression indicated that these four predictors explained $41.1 \%$ of the variance $(\mathrm{F}=59.95, p<.001)$. It was found that self- esteem $(\beta=.45, p<.001)$, depression $(\beta=-.18$, $p<.001)$, educational level $(\beta=.12, p=.004)$, and AUDIT $(\beta=-.10, p=.030)$ significantly predicted life satisfaction in baby-boomer men with drinking problem.

\section{DISCUSSION}

This study was conducted to identify factors influencing life satisfaction in Korean baby-boomer men with drinking problems. Among 755 Korean baby-boomer men participating in the 7 th Korean Welfare Penal Study, 349 (46.2\%) men reported problem drinking in the previous year. The gender difference in problem drinking was consisted with previous studies, which showed higher rates of problem drinking in men than women (Kim, 2006; Park et al., 2011). Additionally, $13.1 \%$ of the elderly in a previous study that used 11 points as the cutoff point of AUDIT scores were classified as problem drinkers (Yoon et al., 2010). In our study, $28.5 \%$ of baby boom men would be classified as problem drinkers if 11 points were used as the cutoff point to select the sample. Although we used a different measure to identify problem drinkers, Ryu, Crespi, and Maxwell (2013) reported that $21.2 \%$ of male adults engaged high-risk drinking. As a result, the prevalence of problem drinking in baby-boomer men is much higher compared to other populations, such as older adults and general male adults. Korean baby-boomers still play pivotal roles in various settings. They are actively involved in social relationship, which could increase the likeli- 
Table 3. Differences in Life Satisfaction by Demographic Characteristics

\begin{tabular}{|c|c|c|c|c|}
\hline \multirow{2}{*}{ Characteristics } & \multirow{2}{*}{ Categories } & \multicolumn{3}{|c|}{ Life satisfaction } \\
\hline & & $\mathrm{M} \pm \mathrm{SD}$ & $\mathrm{t}$ or $\mathrm{F}$ & $p$ \\
\hline Age (year) & $\begin{array}{l}50 \sim 52 \\
53 \sim 55 \\
56 \sim 58\end{array}$ & $\begin{array}{l}23.33 \pm 3.96 \\
23.06 \pm 4.13 \\
23.17 \pm 3.98\end{array}$ & 0.14 & .896 \\
\hline Marital status & $\begin{array}{l}\text { Yes } \\
\text { No }\end{array}$ & $\begin{array}{l}23.72 \pm 3.63 \\
20.35 \pm 4.67\end{array}$ & 6.42 & $<.001$ \\
\hline Occupation & $\begin{array}{l}\text { Yes } \\
\text { No }\end{array}$ & $\begin{array}{l}23.75 \pm 3.61 \\
19.12 \pm 4.49\end{array}$ & 7.56 & $<.001$ \\
\hline Educational level & $\begin{array}{l}\geq \text { Elementary school }^{\mathrm{a}} \\
\text { Middle school }^{\mathrm{a}} \\
\text { High school } \\
\leq \text { College }^{\mathrm{b}}\end{array}$ & $\begin{array}{l}21.72 \pm 4.10 \\
22.10 \pm 3.55 \\
23.29 \pm 4.03 \\
24.89 \pm 3.72\end{array}$ & $\begin{array}{l}9.50 \\
a<b\end{array}$ & $<.001$ \\
\hline
\end{tabular}

Table 4. Correlations among AUDIT, Depression, Self-esteem, and Life Satisfaction

$(N=349)$

\begin{tabular}{|c|c|c|c|c|}
\hline \multirow{2}{*}{ Variables } & AUDIT & Depression & Self-esteem & Life satisfaction \\
\hline & $r(p)$ & $r(p)$ & $r(p)$ & $r(p)$ \\
\hline AUDIT & 1.00 & & & \\
\hline Depression & $.24(<.001)$ & 1.00 & & \\
\hline Self-esteem & $-.30(<.001)$ & $-.52(<.001)$ & 1.00 & \\
\hline Life satisfaction & $-.28(<.001)$ & $-.45(<.001)$ & $.60(<.001)$ & 1.00 \\
\hline
\end{tabular}

AUDIT=Alcohol use disorders identification test.

Table 5. Factors Influencing Life Satisfaction

$(N=349)$

\begin{tabular}{|c|c|c|c|c|c|}
\hline Variables & B & SE & $\beta$ & $\mathrm{t}$ & $p$ \\
\hline \multicolumn{6}{|l|}{ (Constant) } \\
\hline Self-esteem & .44 & .05 & .45 & 8.86 & $<.001$ \\
\hline Depression & -.17 & .05 & -.18 & -3.62 & $<.001$ \\
\hline Educational level & .49 & .17 & .12 & 2.90 & .004 \\
\hline \multirow[t]{2}{*}{ AUDIT } & -.07 & .03 & -.10 & -2.18 & .030 \\
\hline & & \multicolumn{4}{|c|}{$\mathrm{R}^{2}=.411$, Adjust $\mathrm{R}^{2}=.404, \mathrm{~F}=59.95, p<.001$} \\
\hline
\end{tabular}

AUDIT=Alcohol use disorders identification test.

hood of high-risk drinking. Thus, it is necessary to develop an intervention program to change their drinking behaviors.

Life satisfaction was different by marital status, occupation, and educational levels in this study. People with a job showed higher life satisfaction in this study. Since they may have higher economic status, so their satisfactions with family income, living environment, and leisure time could be higher compared to those without job. Chung and Lee (2012) reported that life satisfaction in baby boomers differed by educational levels and marital status. Consisted with our study, baby boomers with high educational level and with a partner showed high level of life satisfaction. As a result, considering their positions in the family and society, the relationships with others may be important for Korean baby-boomer men with drinking problems. The roles of the closed ones, such as their partner or coworkers, may be important to 
increase life satisfaction in baby-boomer men, and furthermore, the program that would include the closed ones can help reduce problem drinking in baby-boomer men. Consisted with previous studies, baby-boomer men with more drinking problem reported lower life satisfaction (Donovan et al., 2005; Strine et al., 2008). Drinking could affect their physical and psychological health status, as well as their social relationships. However, Kwon (2009) reported that problem drinking was not associated with life satisfaction directly but via depression and self-esteem as mediating factors.

Life satisfaction was associated with self-esteem and depression in this study. More depressed persons reported lower life satisfaction, while people with higher self-esteem reported higher life satisfaction. These results were consisted with previous studies (Lee, Kim, \& Oh, 2003; Park, Jin, \& Heo, 2011; Park \& Song, 2012). In a previous study with older people, life satisfaction had a negative relationship with depression, and a positive relationship with self-esteem, particularly self-esteem mediated the relationship between depression and life satisfaction (Kim \& Kim, 2008). In Kwon's (2009) study, depression and self-esteem mediated the relationship between problem drinking and life satisfaction in older adults. Thus, it appears that enhancing self-esteem and reducing depressive symptoms could improve life satisfaction in people with drinking problem. Thus, it is necessary to examine the mediating effects of self-esteem and depression in the relationship between problem drinking and life satisfaction.

This study has some limitations. This study used a secondary analysis with a part of the data of the 7 th Korean Welfare Penal Study that was selected based on our research questions. Some socio-demographic variables that might influence life satisfaction were not included in this study. Thus, it is necessary to examine the relationship between life satisfaction and other sociodemographic characteristics in baby-boomer men. In addition, few people with depressive symptoms were included in this study. Thus, future study needs to examine the relationship between depression and life satisfaction in baby-boomer men with various levels of depression.

\section{CONCLUSION}

The study aimed to identify factors influencing life satisfaction in Korean baby-boomer men with drinking problems to contribute to the development of programs designed to reduce problem drinking. The results of this study showed that life satisfaction had a positive relationships with self-esteem and educational level, while it had a negative relationship with depression and levels of problem drinking. Future studies should examine the direct and indirect effects of self-esteem on the relationship between depression and life satisfaction in Korean baby-boomer men with drinking problems.

\section{REFERENCES}

Babor, T. F., Higgins-Biddle, J. C., Saunders, J. B., \& Monteiro, M. G. (2001). The Alcohol Use Disorders Identification Test: Guidelines for use in primary care. Retrieved from http:// growyourwellness.com/sites/default/files/pdf/AUDIT\% 20test $\% 20$ guidelines.pdf

Chung, S. D., \& Lee, H. H. (2012). Life satisfaction for babyboomers: Compare 1998 with 2008. Journal of Welfare for the Aged, 55, 105-131.

Colliver, J. D., Compton, W. M., Gfroerer, J. C., \& Condon, T. (2006). Projecting drug use among aging baby boomers in 2020. Annals of Epidemiology, 16(4), 257-265. http://dx. doi.org/10.1016/j.annepidem.2005.08.003

DHHS. (2000). Special report to the U.S. congress on alcohol and health: Highlights from current research (NIH Publication No. 00-1583). Washington: National Institutes of Health, National Institute on Alcohol Abuse and Alcoholism. Retrieved from http://pubs.niaaa.nih.gov/publications/10report/intro. pdf.

Donovan, D., Mattson, M. E., Cisler, R. A., Longabaugh, R., \& Zweben, A. (2005). Quality of life as an outcome measure in alcoholism treatment research. Journal of Studies on Alcohol. Supplement, 15, 119-139; discussion 192-193.

Hoe, M., \& Son, J. (2011). The effect of poverty on longitudinal relationship between change of problem drinking and change of self-esteem in middle aged women. Mental Health \& Social Work, 37, 89-116.

Jung, K. H. (2012). An outlook of baby boomers' old age life. Health Welfare Policy Forum, 187, 40-49.

Kim, G. S. (2006). A study on the relationship between family functions and coping behaviors with the alcoholic patients' clinical history. Journal of Social Welfare Development, 12 (1), 1-24.

Kim, H. O. (2011). Comparison of medical expenses by disease between baby boomers and older people. Master's degree, Yonsei University, Seoul.

Kim, H. S. (2002). A study on epistemology of Korean elder's suicidal thought. Journal of the Korea Gerontological Society, 22(1), 159-172. 
Kim, K. H., \& Kim, J. H. (2008). The effects of self-esteem on the relationship between the elderly depression and life satisfaction. Family and Culture, 20(4), 95-116.

Koenig, H. G., George, L. K., \& Schneider, R. (1994). Mental health care for older adults in the year 2020: A dangerous and avoided topic. The Gerontologist, 34(5), 674-679. http:// dx.doi.org/10.1093/geront/34.5.674

Kwon, H. J., \& Kim, S. O. (2004). A study of depression, drinking motives, drinking problem in men. Chung-Ang Journal of Nursing, 8(1), 119-128.

Kwon, H. S. (2009). Effects of problem drinking of elderly on life satisfaction mediated by depression and self-esteem: A latent means analysis application between poor and nonpoor elderly. Journal of Korean Gerontological Society, 29(4), 1521-1538.

Kwon, H. S., \& Sung, H. J. (2010). Effects of problem drinking of adult on depression: Gender difference. Social Science Discussion \& Policy, 3(1), 147-167.

Kwon, J. D., Kim, Y. J., \& Um, T. Y. (2011). Suicidal ideation among older adults who live alone with care services: A moderating effect of alcohol drinking in the relationship between previous suicidal attempts and suicidal ideation. Journal of Welfare for the Aged, 51, 297-320.

Lee, B. J., \& Lee, J. S. (2007). Mediating effects of alcohol-induced stress in the relation between alcohol use and depressive symptoms. Social Science Research Review, 23(2), 193-212.

Lee, J. I., Kim, K. H., \& Oh, S. H. (2003). Depression and life satisfaction of middle-aged man. Korean Journal of Adult Nursing, 15(3), 422-431.

Ministry of Health and Welfare. (2012). Korean health statistics 2011: Korean National Health and Nutrition Examination Survey (KNHANES V-2). Seoul: Korea Centers for Disease Control and Prevention.

Noh, A. Y., \& Jeong, M. (2003). The factors that influence college students' drinking problems. Korean Journal of Counseling, $4(1), 5-18$.
Park, B. S., Jin, H. M., \& Hoe, M. (2011). The relationship of depression and life satisfaction on male alcoholics: Exploring on the roles of family function and family support. Mental Health \& Social Work, 38, 172-204.

Park, Y. S., \& Song, J. Y. (2012). The moderating effect of social supports on the relationship between depression and satisfaction of life of the older man with a chronic disease. Korean Journal of Social Welfare Education, 17, 79-96.

Radloff, L. S. (1977). The CES-D scale: A self-report depression scale for research in the general population. Applied Psychological Measurement, 1, 385-401.

Rosenberg, R. L. (1979). Conceiving the self. New York: Basic Book.

Ryu, S. Y., Crespi, C. M., \& Maxwell, A. E. (2013). Drinking Patterns Among Korean Adults: Results of the 2009 Korean Community Health Survey. Journal of Preventive Medicine and Public Health, 46(4), 183-191.

Statistics Korea. (2010a). 2010 Census, Retrieved November 2, 2013, from http://kosis.kr/statisticsList/statisticsList_01List. jsp?vwcd=MT_ZTITLE\&parentId=A

Statistics Korea. (2010b). 2009 Results of Korean causes of death. Retrieved September 11, 2013, from http://stat.kpha.or.kr/ stat/t3/stat.php?sid=3_1

Strine, T., Chapman, D., Balluz, L., Moriarty, D., \& Mokdad, A. (2008). The associations between life satisfaction and healthrelated quality of life, chronic illness, and health behaviors among U.S. community-dwelling adults. Journal of Community Health, 33(1), 40-50. http://dx.doi.org/10.1007/s10 900- 007-9066-4

Weatherspoon, A. J., Park, J. Y., \& Johnson, R. C. (2001). A family study of homeland Korean alcohol use. Addictive Behaviors, 26(1), 101-113. http://dx.doi.org/10.1016/S03064603(00)00093-9

Yoon, M. S., Kim, S. H., \& Chae, W. S. (2010). The effects of alcohol use, mental health factors on seniors' ideation of suicide. Journal of Korean Alcohol Science, 11(1), 27-44. 